\title{
PENGARUH NILAI UTILITARIAN,NILAI HEDONIS, PENGALAMAN PELANGGAN, KEPERCAYAAN MEREK TERHADAP LOYALITAS PELANGGAN SONNY VAIO
}

\author{
Erik Wardhana *) \\ *) Dosen Tetap Prodi Studi .Manajemen Fakultas Ekonomi \\ Universitas Krisnadwipayana Jakarta \\ Email : wardhana.pertama@gmail.com
}

\begin{abstract}
The background of this research was examined the influences of trust and affect on increasing likelihood to purchase luxury brands. The objectives of this research was analyzed the effect of utilitarian value on brand loyalty, the effect to hedonic value on brand loyalty, the effect of customer experience on brand loyalty, the effect of brand trust on brand loyalty. A sampling with purposive sampling techniques of fourty four customer of Sony Vaio as the respondents provided the data that were analyzed for this study. Using a sub-set of the sample consisting of fourty four customer of Sony Vaio was used to test four hypothesized relationships in the model. The result of this research conclude that the effect of positively and significantly utilitarian value, hedonic value, customer experience, brand trust toward brand loyalty on Sony vaio consumer.
\end{abstract}

\section{Keywords: Utilitarian Value, Hedonic Value, Customer Experience, Brand Trust and Brand Loyalty}

\section{PENDAHULUAN}

Merek dan produk merupakan dua hal yang tidak dapat dipisahkan. Terkadang konsumen menyebut sebuah merek, padahal yang dimaksudkan adalah produk ataupun sebaliknya. Loyalitas merek untuk menggambarkan seberapa kuat preferensi seorang konsumen terhadap sebuah mereka apabila dibandingkan dengan merek lainnya. Loyalitas merek dianggap sebagai suatu ukuran keterkaitan pelanggan kepada sebuah mereka. Ukuran ini mampu memberikan gambaran tentang mungkin tidaknya seorang pelanggan beralih ke merek lain yang ditawarkan oleh para pesaing lainnya, terutama jika pada merek tersebut didapati adanya perubahan, baik menyangkut harga ataupun atribut lainnya. Seorang pelanggan yang sangat loyal kepada merek tidak akan dengan mudah memindahkan pembeliannya ke merek lain, apa pun yang terjadi dengan merek tersebut. Apabila loyalitas pelanggan terhadap suatu merek meningkat, kerentanan kelompok pelanggan tersebut dari ancaman dan serangan merek produk pesaing dapat dikurangi. Loyalitas merek ditunjukkan dengan adanya kedekatan pelanggan terhadap merek produk atau jasa (Chalal dan Bala, 2010).

Loyalitas merek merupakan tujuan inti yang diupayakan pemasar kepada konsumen terhadap merek produk yang dibelinya. Dengan adanya loyalitas merek, pemasar dapat mengurangi biaya promosi dan dapat dipastikan akan mendapatkan manfaat yang besar, Giddens (2002) berpendapat bahwa konsumen yang loyal terhadap suatu merek memiliki ciriciri memiliki komitmen pada merek tersebut, berani membayar lebih pada merek tersebut bila dibandingkan dengan merek yang lain, akan merekomendasikan merek tersebut pada orang lain, tidak melakukan pertimbangan dalam melakukan pembelian kembali produk tersebut, selalu mengikuti informasi yang berkaitan merek tersebut dan mereka dapat menjadi semacam juru bicara dari merek tersebut dan mereka selalu mengembangkan hubungan 
dengan merek tersebut. Loyalitas merek diwujudkan sebagai pihan yang dilakukan konsumen untuk membeli merek tertentu dibandingkan merek yang lain dalam satu kategori produk (Gidden, 2002).

Loyalitas terhadap merek dapat terbentuk karena pelanggan merasakan adanya nilai kegunaan dari suatu produk atau jasa (Hu dan Chuang, 2012). Setiap pelanggan pun memiliki kebutuhan yang ingin dipenuhi. Kebutuhan merupakan alasan bagi pelanggan yang memiliki pandangan mencari nilai kegunaan dari produk atau jasa. Nilai kegunaan dari suatu produk atau jasa dapat dilihat dari nilai fungsional atau kinerja dari produk atau jasa yang dibeli oleh pelanggan. Apabila pelanggan menilai produk atau jasa yang dibelinya memiliki kinerja yang baik dan melebihi harapan yang dimilikinya maka pelanggan pun akan merasa loyal terhadap merek produk atau jasa yang dibelinya. Pelanggan lebih menilai inovasi dan keunggulan yang dimiliki oleh produk atau jasa dibandingkan dengan pesaingnya. Nilai kegunaan yang diperoleh oleh pelanggan menunjukkan bahwa produk atau jasa tersebut dapat memberikan kemudahan di dalam menyelesaikan pekerjaan. Dengan adanya pertimbangan nilai kegunaan yang diperoleh dari produk atau jasa dapat menciptakan kedekatan yang timbul dari pelanggan untuk tetap menjalin hubungan baik dengan perusahaan penyedia jasa. Pelanggan yang mencari fungsi ketika membeli produk atau jasa terlihat pelanggan membeli produk atau jasa secara rasional. Ketika pelanggan merasakan adanya manfaat dari produk atau jasa yang dibelinya maka pelanggan tersebut akan memiliki komitmen yang kuat untuk membeli produk atau jasa. Komitmen yang kuat ditunjukkan dengan adanya pembelian produk atau jasa pada perusahaan yang sama. Pelanggan yang memiliki konsep utilitarian atau mencari nilai kegunaan ketika membeli produk atau jasa dapat lebih menghemat uang yang dikeluarkan dengan cara memaksimalkan nilai fungsional dari suatu produk atau jasa (Rintamaki, et.al., 2007).

Loyalitas terhadap merek pun dapat ditentukan oleh nilai hedonis yang dimiliki oleh para pelanggan ketika membeli suatu produk atau jasa (Lee dan Overby, 2004). Nilai hedonis dapat diungkapkan dengan adanya nilai kesenangan yang diperoleh oleh pelanggan ketika membeli produk atau jasa. Pelanggan yang memiliki nilai hedonis tidak mempertimbangkan manfaat yang diperoleh ketika membeli suatu merek produk atau jasa. Pelanggan yang memiliki nilai hedonis maka pelanggan tersebut hanya akan mencari kebahagiaan dan kesenangan saja sehingga pelanggan tetap ingin membeli produk atau jasa. Nilai hedonis timbul karena adanya penilaian secara emosional terhadap atribut yang dimiliki oleh suatu produk atau jasa (Sindhav dan Adidam, 2012).

Loyalitas terhadap merek timbul karena pelanggan memiliki pengalaman mengenai keunggulan dari produk atau jasa yang dijualoleh perusahaan penyedia jasa. Loyalitas terhadap merek timbul karena pelanggan memiliki kesan yang baik terhadap produk atau jasa yang dibelinya. Dengan adanya slogan pelanggan adalah raja maka perusahaan harus menciptakan pengalaman yang baik kepada pelanggan dengan memberikan layanan jasa yang maksimal. Pengalaman yang baik ditunjukkan melalui kesan yang baik timbul setelah pelanggan merasakan manfaat produk atau jasa melampaui harapan yang dimilikinya. Pengalaman merek terdiri dari semua unsur yang dilihat oleh pelanggan, seperti produk itu sendiri, logo, simbol, kemasan, brosur dan iklan. Pengalaman merek bersifat tidak dinamis karena tidak diciptakan pada saat pelanggan berinteraksi dengan perusahaan. Pengalaman timbul karena adanya penilaian subyektif yang dilakukan oleh pelanggan setelah merasakan ketika menggunakan produk atau jasa. Peneliti sebelumnya berpendapat bahwa konsumen memiliki pengalaman pelanggan timbul ketika pelanggan mencari produk yang tepat, melakukan pembelian, dan menggunakannya (Aarnould, Price, dan Zinkhan, 2002; Brakus, Schmitt, dan Zhang, 2008).

Telah dijelaskan bahwa brand loyalty ditentukan oleh adanya brand trust (Chaudhuri dan Holbrook, 2001). Loyalitas merek yang dimiliki oleh pelanggan ditentukan oleh 
keyakinan dari dalam diri pelanggan dengan produk atau jasa yang dibelinya. Delgado, et.al., (2003) menemukan bahwa kepercayaan merek sebagai dugaan atau harapan dengan keyakinan akan kehandalan terhadap suatu merek dalam situasi yang memiliki resiko bagi pelanggan. Kepercayaan menunjukkan bahwa adanya keyakinan terhadap kemampuan perusahaan di dalam menyampaikan atau menjual produk atau jasa kepada pelanggan. Kepercayaan adalah dugaan atau harapan bahwa merek tersebut dapat diandalkan untuk berperilaku murah hati dan responsif terhadap kebutuhan seseorang (Park et.al., 2006).

Penelitian yang dilakukan oleh Song, et.al., (2012) meneliti mengenai utilitarian value, hedonic value, brand satisfaction, brand trust, brand affect, and brand risk. Beda penelitian sebelumnya adalah penelitian mengenai customer experience untuk menunjukkan adanya kedekatan psikologis dan perasaan subyektif terhadap produk atau jasa (Johnston dan Kong, 2011).

\section{Tujuan dan Manfaat Penelitian}

Sesuai dengan perumusan masalah yang diungkapkan diatas maka tujuan penelitian adalah :

1. Untuk menganalisis pengaruh utilitarian value terhadap brand loyalty.

2. Untuk menganalisis pengaruh hedonic value terhadap brand loyalty.

3. Untuk menganalisis pengaruh customer experience terhadap brand loyalty.

4. Untuk menganalisis pengaruh brand trust terhadap brand loyalty.

Penelitian ini memiliki manfaat :

1. Bagi Perusahaan

Dengan menciptakan loyalitas merek maka dapat meningkatkan profitabilitas dan keberhasilan penjualan yang dicapai oleh perusahaan.

2. Bagi peneliti selanjutnya

Penelitian ini memberikan manfaat bagi peneliti selanjutnya agar meneliti variabel lainnya seperti perceived value dan brand affect.

\section{LANDASAN TEORI}

\section{Utilitarian Value}

Chaudhuri, et,a., (2010) memberikan pengertian utilitarian value adalah suatu penilaian terhadap instrumen atau atribut dari produk atau jasa yang dijual oleh perusahaan penyedia jasa. Sindhav dan Adidam (2012) berpendapat bahwa utilitarian value adalah suatu nilai yang diperoleh pelanggan untuk mengatasi masalah. Sindhav dan Adidam (2012) pun menjelaskan bahwa utilitarian value mempertimbangkan aspek nilai ekonomis dari uang dan pelanggan mempertimbangkan untuk mencari uang dan menghemat waktu. Sarkar (2011) mendefinisikan utilitarian value adalah suatu nilai kenyamanan, kualitas yang baik, berbagai macam produk, mempertimbangkan alasan harga yang dicari oleh pelanggan ketika membeli produk atau jasa. Pillai dan Mukherjee (2011) mendefinisikan utilitarian value adalah nilai kegunaan dari produk atau jasa yang dicari oleh pelanggan.

Choe dan Min (2011) mendefinsikan utilitarian value adalah suatu keputusan yang dimiliki oleh pelanggan untuk mencari keseluruhan manfaat dari produk atau jasa yang dibelinya. Ryu, Han, dan Jang (2010) mendefinisikan utilitarian value adalah suatu evaluasi yang dilakukan oleh pelanggan terhadap nilai fungsional yang diterima oleh pelanggan setelah melakukan pembelian produk atau jasa. Kim dan Hwang (2012) mendefinisikan utilitarian value adalah suatu nilai yang kegunaan, fungsional dan nilai ekonomis dari suatu produk atau jasa untuk mengatasi masalah yang dimiliki oleh pelanggan. Yang dan Lee (2010) memberikan pengertian utilitarian value adalah nilai kegunaan fungsional yang diperoleh oleh pelanggan ketika membeli produk atau jasa. 
Hal ini dapat disimpulkan bahwa utilitarian value adalah nilai yang diperoleh pelanggan ketika berbelanja produk atau jasa berupa nilai kegunaan, nilai ekonomis, dan nilai fungsional. Cardoso dan Pinto (2010) menemukan tujuan dari pelanggan melakukan penilaian terhadap utilitarian value dari produk atau jasa yang dibelinya adalah untuk menilai atribut, hasil, dan efisiensi yang dimiliki oleh produk atau jasa dibandingkan pesaing lainnya. Kang dan Poaps (2010) menemukan tujuan dari pelanggan melakukan penilaian terhadap utilitarian value adalah untuk meningkatkan fashion leadership di dalam pembelian pakaian. Irani dan Hanzaee (2011) menyebutkan tujuan dari penilaian utilitarian value adalah shopping satisfaction yang dimiliki oleh pelanggan. Chuang (2012) menyebutkan tujuan dari penilaian utilitarian value adalah untuk membandingkan antara pengorbanan yang dilakukan oleh pelanggan dengan manfaat yang diperoleh pelanggan ketika membeli produk atau jasa.

\section{Hedonic Value}

Menurut Hirschman dan Holbrook, hedonisme berasal dari bahasa Yunani yaitu hedone yang artinya kesenangan atau kenikmatan (O'shaughnessy, 2002). Konsumsi hedonic mengangkat segi perilaku konsumen yang berhubungan dengan multisensory, khayalan dan aspek yang berkenaan dengan suara dari pengalaman seseorang dengan produk (Rintamaki et.al., 2006). Hedonic value adalah suatu keputusan pelanggan dalam berbelanja untuk mencari pengalaman (Overby dan Lee, 2006). Hedonic value adalah suatu nilai belanja yang dimiliki oleh pelanggan untuk mencari hiburan dan kesenangan (Hu dan Chuang, 2012). Kim dan Hwang (2012) memberikan pengertian hedonic value adalah suatu nilai berbelanja produk atau jasa untuk mencari kesenangan dan Hiburan. Pillai dan Mukherjee (2011) mendefinisikan hedonic value adalah nilai kesenangan yang diperoleh oleh pelanggan ketika membeli produk atau jasa. Ryu, Han, dan Jang (2010) mendefinisikan hedonic value adalah suatu nilai belanja yang dimiliki oleh pelanggan hanya untuk mencari pengalaman seperti fantasi, mencari pengalaman, stimulasi-sensori, kenikmatan, kesenangan, keingintahuan, dan hiburan (Scarpi, 2006). Irani dan Hanzaee (2012) mendefinisikan hedonic value adalah suatu penilaian yang dilakukan secara subyektif dan individualistis dari aktivitas berbelanja untuk mencari kesenangan dan hiburan.

Hal ini dapat disimpulkan bahwa hedonic value adalah suatu penilaian perasaan emosional yang dirasakan konsumen dari pengalaman berbelanja produk atau jasa yang lebih bersifat subyektif dan pribadi berupa penilaian kesenangan, kegembiraan dan hiburan. Cardoso dan Pinto (2010) menemukan tujuan pelanggan memiliki hedonic value adalah untuk mencari kesenangan seperti berbelanja dengan mengajak keluarga untuk berjalan-jalan di pusat perbelanjaan, berbelanja sebagai aktivitas rekreasi. Bigne, et.al., (2008) menemukan tujuan pelanggan memiliki hedonic value adalah untuk menciptakan kesenangan dan kegembiraan. Kim dan Hwang (2012) menjelaskan bahwa tujuan pelanggan memiliki hedonic value adalah untuk menilai information quality, design quality, dan connection quality yang dimiliki oleh suatu website berbelanja.

Bigne, et.al., (2008) menemukan fungsi dari pembentukan hedonic value yang dimiliki oleh pelanggan adalah untuk menciptakan kepuasan pelanggan ketika melakukan aktivitas berbelanja. Hu dan Chuang (2012) menemukan fungsi dari pembentukan hedonic value yang dimiliki oleh pelanggan adalah untuk menciptakan loyalitas bagi nasabah yang melakukan transaksi menggunakan internet banking. Nilai berbelanja yang terdiri dari adventure, gratification, role,value, social, dan idea shopping motivation termasuk ke dalam nilai berbelanja hedonic (Arnold dan Reynold, 2003). Kang dan Poaps (2010) menyatakan dimensi dari hedonic value terdiri dari enjoyment, pleasure, social experience, dan entertainment value. Olsen dan Skallerud (2011) menemukan dimensi yang membentuk hedonic value adalah pleasure, arousal, dan entertainment value. Ryu, Han, dan Jang (2010) menemukan 
dimensi yang membentuk hedonic value adalah fun. Hu dan Chuang (2012) menyebutkan dimensi yang membentuk hedonic value terdiri dari entertainment, sociality, dan escapism.

\section{Customer Experience}

Customer experience adalah suatu akumulasi pengetahuan dan keahlian yang dimiliki oleh pelanggan (Palmer, 2010). Nasermoadeli, Ling, dan Severi (2013) mendefinisikan customer experience adalah suatu sensasi dan pengetahuan yang dimiliki oleh pelanggan ketika berinteraksi dengan perusahaan penyedia jasa. Meyer dan Schwager (2007) mendefinisikan customer experience adalah suatu tanggapan subyektif dan internal yang dimiliki oleh para pelanggan dengan perusahaan secara langsung dan tidak langsung. Gentile et.al., (2007) beranggapan bahwa customer experience adalah suatu interaksi yang timbul antara pelanggan dengan perusahaan penyedia jasa. Grewal, Levy, dan Kumar (2009) mendefinisikan customer experience adalah suatu pendekatan yang dilakukan oleh pelanggan agar meningkatkan keterlibatan secara emosional, perasaan, kognitif terhadap perusahaan penyedia jasa. Menurut Johnston dan Kong (2011), customer experience adalah sesuatu yang diterima oleh pelanggan ketika membeli dari perusahaan penyedia jasa.

Hal ini dapat disimpulkan bahwa customer experience adalah suatu peristiwa yang berkesan dari dalam diri pelanggan terhadap perusahaan penyedia jasa ketika menjual produk atau jasa. Sirapracha dan Tocquer (2012) menyebutkan tujuan dari pembentukan customer experience adalah meningkatkan citra dari merek produk atau jasa yang dijual oleh perusahaan. Stone (2011) menemukan tujuan dari pembentukan customer experience adalah untuk menentukan pengambilan keputusan yang dimiliki oleh para pelanggan. Lutz dan Foong (2008) menemukan tujuan dari pembentukan customer experience adalah untuk menciptakan kepuasan dan loyalitas pelanggan. Mosley (2007) menjelaskan tujuan dari pembentukan customer experience adalah untuk mengelola manajemen merek dari produk atau jasa yang dijual oleh perusahaan. Mascarehas, Kesavan, dan Bernacchi (2006) menyebutkan tujuan dari pembentukan customer experience adalah menciptakan loyalitas pelanggan.

Sirapracha dan Tocquer (2012) menjelaskan fungsi dari pembentukan customer experience adalah untuk meningkatkan interaksi pelanggan untuk tetap menjalin hubungan dengan perusahaan penyedia jasa. Grewal, Levy, dan Kumar (2009) menyebutkan fungsi dari pembentuikan customer experience adalah untuk mengukur aktivitas pemasaran yang dijalankan oleh perusahaan. Palmer (2010) menemukan fungsi dari pembentukan customer experience adalah untuk menciptakan nilai bagi pelanggan dan meningkatkan profitabilitas yang dihasilkan oleh perusahaan. Pucinelli, Gooodstein, Grewal, Price, dan Raghubir (2009) menyebutkan fungsi dari timbulnya customer experience adalah untuk memahami perilaku pelanggan di dalam pengambilan keputusan pembelian produk atau jasa.

\section{Brand Trust}

Menurut Morgan dan Hunt (2002), definisi brand trust adalah : keyakinan seorang pelanggan terhadap kemampuan perusahaan penyedia jasa di dalam memperkenalkan merek produk atau jasa. Dooney dan Canyon (2001) mendefinisikan customer experience adalah suatu proses pembentukan keterlibatan secara kalkulatif untuk memenuhi kewajiban di dalam pembentukan hubungan antara pelanggan dengan merek produk atau jasa. Morman, Zaltmen, dan Desphande (2001), Dooneey dan Canyon (2001) keduanya menekankan bahwa pernyataan "percaya" hanya relevan terjadi pada situasi yang tidak pasti (misalkan dimana terdapat perbedaan besar dan kecil pada suatu merek). Secara keseluruhan Arjub Chanduri dan Hallbrook (2001) menilai kepercayaan terhadap merek sebagai bentuk proses keterlibatan yang telah diduga sepenuhnya dan didasari secara mendalam. 
Hal ini dapatdisimpulkan bahwa customer experience adalah keyakinan dari dalam diri pelanggan mengenai merek produk atau jasa yang dijual oleh perusahaan. Menurut Mowen dan Minnar (2000) mengatakan bahwa bentuk kepercayaan konsumen terhadap suatu merek pada sebagian besar terjadi apabila merek produk tersebut mampu memenuhi self concept, needs, dan value. Self concept merupakan bentuk perasaan dan perkiraan secara keseluruhan dari individu terhadap sebuah objek yang mencerminkan dirinya. Komponen selft concept terdiri dari : 1). Actual self; Bagaimana seseorang atau individu sebenarnya memahami dirinya. 2). Ideal self; Bagaimana seseorang atau individu akan dapat memahami tentang dirinya. 3). Social self; Bagaimana seseorang atau individu percaya bahwa orang lain memahami dirinya. 4). Ideal social self; Bagaimana seseorang atau individu menginginkan orang lain memahami dirinya. 5). Expected self; Menjelaskan bagaimana seseorang akan bersikap atau bertindak. 6). Situational self; Bagaimana sikap atau kepribadian seseorang pada situasi tertentu. 7). Extended self; Konsep kepribadian seseorang atau individu yang termasuk mampu mempengaruhi image kepribadian yang dimiliki individu tersebut. 8). Possible self; Bagaimana seseorang atau individu indin menjadi, akan menjadi, dan takut untuk menjadi orang lain.

Needs (kebutuhan) konsumen berdasarkan teori Maslow terdiri dari lima bagian, yaitu : 1). Physiological needs (kebutuhan fisiologis); Merupakan kebutuhan dasar dan merupakan tingkatan utama dari kebutuhan manusia. 2). Safety and security needs (kebutuhan akan rasa aman); Kebutuhan ini tidak hanya didasarkan atas pertimbangan keamanan fisik, akan tetapi juga rasa aman atas ketertiban, stabilitas, dan pengendalian hidup seseorang dan lingkungan. 3). Social needs (kebutuhan sosial); Kebutuhan ini mencakup kebutuhan akan rasa sayang, rasa saling memiliki, keinginan untuk bisa diterima dalam lingkungan pergalan atau lingkungan sosial. 4). Egoistic needs (kebutuhan sifat ego); Kebutuhan ini dapat berupa orientasi ke dalam atau inward orientation dan ke luar atau outward orientation atau bahkan keduanya. Orientasi ke dalam mengarahkan kepada suatu gambaran kebutuhan individu akan kebebasan, kesuksesan, pengakuan diri, penerimaan diri, dan kepuasan pribadi terhadap pekerjaan dan telah dilaksanakan. Sedangkan orientasi keluar mengarahkan kepada suatu gambaran terhadap kebutuhan reputasi, status. Kesuksesan dan keberhasilan seseorang merupakan gambaran yang merefleksikan dari orientasi keluar ini. 5). Need for selft actualitation; Kebutuhan ini mengarah pada keinginan individu untuk mewujudkan sesuatu hal yang dapat dilakukan untuk dicapai atau mencapai kepuasan yang telah didambakan.

Menurut Mowen dan Minar (2001:226) value (nilai) yang diinginkan oleh konsumen terhadap suatu produk meliputi : 1). Internal value; Nilai internal individu meliputi kepuasan pribadi (self fulfillment) perasaan akan kesempurnaan (sense ofaccomplishment), penghargaan diri (self respect) dan kesenangan (excitement). 2). External value; Nilai external individu meliputi perasaan memiliki (regards of sense belonging) perasaan dihargai dengan baik (being well of respecting), dan keamanan (security). 3). Internal orientation value; Orientasi hubungan antar pribadi seperti rasa nikmat dan kesenangan.

\section{Brand Loyalty}

Brand loyalty dengan mudah dpat diidentifikasi untuk dianalisis dengan mengandalkan pada empat ciri utama, yaitu: (1) Konsumensi produk atau jasa dari konsumen saat ini, yang mana dilihat dari volume dan frekuensi konsumsi dari pelanggan saat ini; (2) Proporsi dari produk atau jasa yang dikonsumsi oleh pelanggan pada retail atau toko tertentu; (3) Kemungkinan konsumen untuk melakukan pembelian kembali; (4) Waktu yang diperkirakan pelanggan berpindah ke produk atau jasa yang lain (Shauka, 2009). Pada penelitian terdahulu, para peneliti biasanya menggunakan perilaku berlangganan sebagai metode untuk mengukur loyalitas merek (brand loyalty). Tetapi, sudah ditemukan satu cara terbaik untuk mengukur loyalitas merek (brand loyalty), yaitu dengan mengukur loyalitas afektif (affective loyalty) 
(Lin, 2000). Menurut Fajrianti (2005), pelanggan yang loyal terhadap suatu merek memiliki ciri-ciri sebagai berikut: (1) Memiliki komitmen terhadap merek tersebut; (2) Berani membayar lebih terhadap merek tersebut bila dibandingkan dengan merek yanglain; (3) Akan merekomendasikan merek tersebut kepada orang lain; (4) Dalam melakukan pembelian kembali produk tersebut tidak melakukan pertimbangan; (5) selalu mengikuti informasi yang berkaitan dengan merek tersebut; (6) Konsumen dapat menjadi juru bicara dari merek tersebut dan selalu mengembangkan hubungan dengan merek tersebut.

Hal ini dapat disimpulkan bahwa brand loyalty adalah komitmen terdalam yang dimiliki oleh pelanggan untuk melakukan pembelian kembali suatu produk atau jasa di masa yang akan datang.

\section{METODE PENELITIAN}

\section{Rancangan Penelitian}

Penelitian ini sesuai dengan penelitian yang dilakukan oleh Song, Hur, dan Kim (2012) yang bertujuan untuk menganalisis pengaruh utilitarian value, hedonic value, customer experience, brand trust terhadap brand loyalty. Data diperoleh dengan menyebarkan kuesioner mengenai pengaruh utilitarian value, hedonic value, customer experience, brand trust terhadap brand loyalty kepada 44 pelanggan yang membeli Lap Top Sony Vaio di Bekasi Cyber Park.

\section{Variabel dan Pengukuran}

Variabel yang diteliti adalah utilitarian value, hedonic value, customer experience, brand trust, dan brand loyalty. Adapun pengukuran dari masing-masing variabel yang menggunakan beberapa indikator pernyataan sebagai berikut :

\section{Utilitarian Value}

Utilitarian value diukur menggunakan Skala Likert lima point dimana tersusun dari skala 1 menunjukkan sangat tidak setuju, skala 2 menunjukkan tidak setuju, skala 3 menunjukkan cenderung setuju, skala 4 menunjukkan setuju, dan skala 5 menunjukkan sangat setuju. utilitarian value terbentuk dari empat pernyataan yang diungkapkan oleh Kang dan Poaps (2010) yaitu :

1. Pelanggan memahami pentingnya memiliki rencana untuk membeli laptop Sony Vaio.

2. Ketika pelanggan berbelanja produk laptop Sony Vaio, pelanggan menemukan fitur yang sesuai dengan keperluan saya.

3. Pelanggan akan merasa kecewa apabila pelanggan tidak membeli produk laptop Sony Vaio.

4. Pelanggan mengunjungi toko yang tepat harus diputuskan secara cepat.

\section{Hedonic Value}

Hedonic value diukur menggunakan Skala Likert lima point dimana tersusun dari skala 1 menunjukkan sangat tidak setuju, skala 2 menunjukkan tidak setuju, skala 3 menunjukkan cenderung setuju, skala 4 menunjukkan setuju, dan skala 5 menunjukkan sangat setuju. Hedonic value terbentuk dari sepuluh pernyataan yang diungkapkan oleh Irani dan Hanzaee (2011) yaitu :

1. Berbelanja laptop Sony Vaio menyenangkan

2. Pelanggan melanjutkan untuk berbelanja laptop Sony Vaio karena pelanggan menginginkannya

3. Dibandingkan dengan laptop lainnya, waktu berbelanja yang dihabiskan oleh pelanggan sangat menyenangkan. 
4. Pelanggan menikmati keunggulan fitur terbaru dari laptop Sony Vaio

5. Pelanggan menikmati berbelanja sehingga pelanggan membeli lebih dari satu jenis laptop Sony Vaio

6. Pelanggan memiliki banyak waktu untuk berbelanja laptop Sony Vaio

7. Selama aktivitas berbelanja, saya senang melakukan aktivitas di dalam mencari laptop yang baik.

8. Ketika pelanggan berbelanja, pelanggan merasa lupa akan masalah yang dihadapi

9. Ketika pelanggan berbelanja, pelanggan merasa berpetualang

10. Berbelanja adalah waktu yang menyenangkan bagi pelanggan.

\section{Customer Experience}

Customer experience diukur menggunakan Skala likert lima point dimana tersusun dari skala 1 menunjukkan sangat tidak setuju, skala 2 menunjukkan tidak setuju, skala 3 menunjukkan cenderung setuju, skala 4 menunjukkan setuju, dan skala 5 menunjukkan sangat setuju. Customer experience terbentuk dari empat pernyataan yang diungkapkan oleh Rose, Clark, Samouel, dan Hair (2012) yaitu :

1. Saya membeli laptop Sony Vaio karena saya memiliki hobi berbelanja

2. Saya mencari pengalaman yang berbeda ketika saya membeli laptop Sony Vaio

3. Ketika saya berbelanja laptop Sony Vaio, saya mengetahui keunggulan fitur laptop Sony Vaio dibandingkan pesaing lainnya.

\section{Brand Trust}

Brand trust diukur menggunakan Skala Likert lima point dimana tersusun dari skala 1 menunjukkan sangat tidak setuju, skala 2 menunjukkan tidak setuju, skala 3 menunjukkan cenderung setuju, skala 4 menunjukkan setuju, dan skala 5 menunjukkan sangat setuju. Brand trust terbentuk dari tiga pernyataan yang diungkapkan oleh Song, Hur, dan Kim (2012) yaitu :

1. Saya merasa yakin terhadap merek laptop Sony Vaio.

2. Saya memilih untuk tetap membeli laptop Sony Vaio

3. Laptop Sony Vaio adalah merek laptop yang terpercaya.

\section{Brand Loyalty}

Brand loyalty diukur menggunakan Skala likert lima point dimana tersusun dari skala 1 menunjukkan sangat tidak setuju, skala 2 menunjukkan tidak setuju, skala 3 menunjukkan cenderung setuju, skala 4 menunjukkan setuju, dan skala 5 menunjukkan sangat setuju. Brand loyalty terbentuk dari tiga pernyataan yang diungkapkan oleh Song, Hur, dan Kim (2012) yaitu :

1. Saya akan tetap mengunjungi penjual laptop Sony Vaio di masa yang akan datang

2. Saya akan membeli Sony Vaio di masa yang akan datang

3. Saya akan merekomendasikan laptop Sony Vaio kepada teman dan kerabat.

\section{Sampel dan Pengumpulan Data}

Jumlah sampel dalam penelitian ini dilakukan dengan cara menyebarkan kuesioner kepada 44 pelanggan yang membeli laptop Sony Vaio di Bekasi Cyber Park. Teknik pengambilan sampel yang digunakan adalah purposive sampling. Teknik pengumpulan data yang digunakan adalah teknik pengumpulan data purposive sampling adalah suatu teknik pengumpulan data berdasarkan kriteria-kriteria penelitian tertentu (Sekaran, 2006). Kriteriakriteria yang ditentukan adalah jenis kelamin, usia, pendapatan yang dimiliki, dan alasan menyukai laptop Sony Vaio. 
Tabel 1

Profil Responden

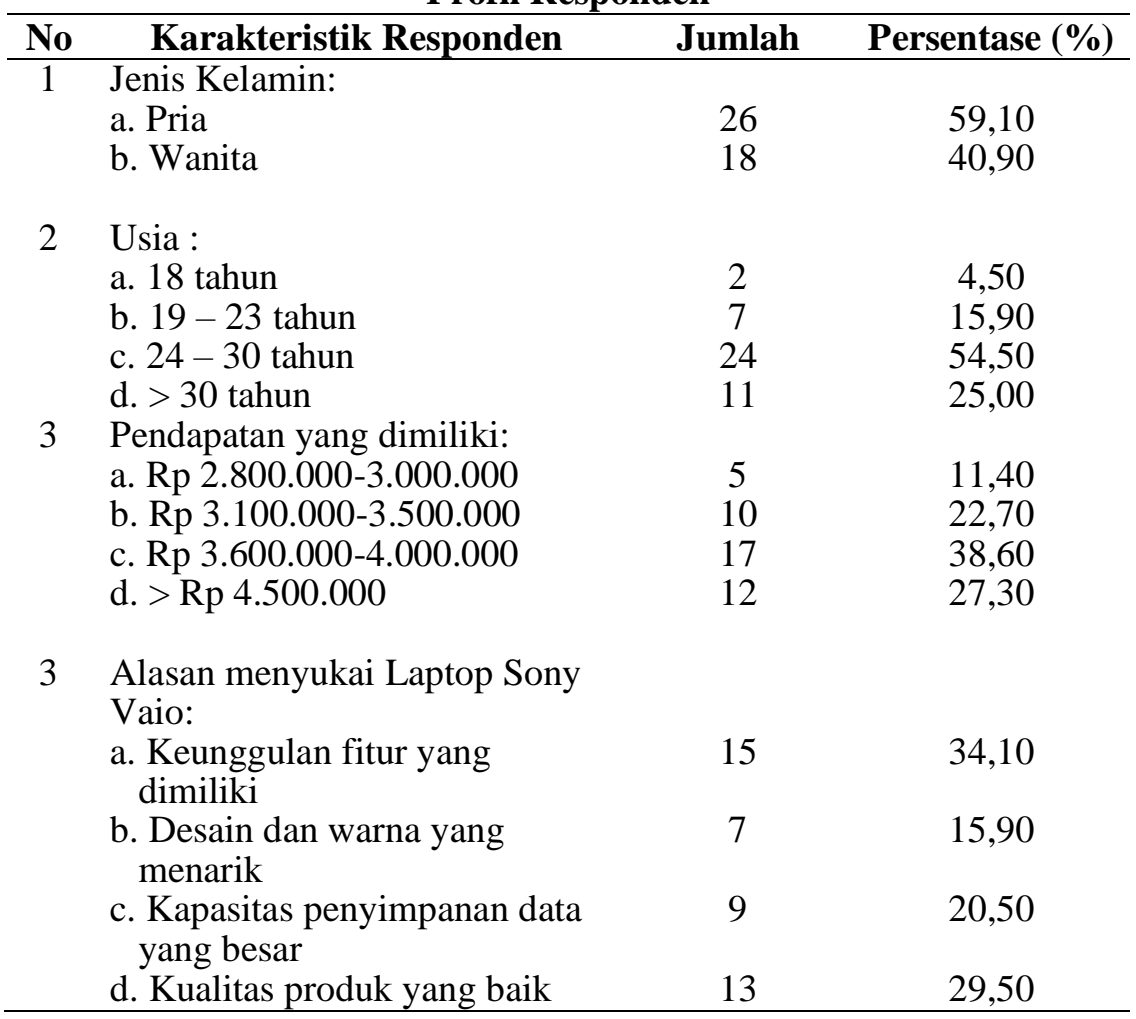

Pada Tabel 1 menunjukkan karakteristik demografis dari responden yang membeli laptop Sony Vaio dimana pelanggan yang memiliki jenis kelamin pria sebanyak 26 responden atau ditunjukkan berdasarkan persentase diperoleh sebesar persen $(59,10 \%)$, sedangkan pelanggan yang memiliki jenis kelamin wanita sebanyak 18 responden atau ditunjukkan berdasarkan persentase diperoleh sebesar 40,90 persen $(40,90 \%)$

Karakteristik demografis dari responden yang membeli laptop Sony Vaio dimana pelanggan yang memiliki usia 18 tahun sebanyak 2 responden atau ditunjukkan berdasarkan persentase diperoleh sebesar 4,50 persen (4,50\%), pelanggan yang memiliki usia antara 19 tahun hingga dengan 23 Tahun sebanyak 7 responden atau ditunjukkan berdasarkan persentase diperoleh sebesar 15,90 persen $(15,90 \%)$, pelanggan yang memiliki usia antara 24 Tahun hingga dengan 30 Tahun sebanyak 24 responden atau ditunjukkan berdasarkan persentase diperoleh sebesar 54,50 persen $(54,50 \%)$, pelanggan yang memiliki usia lebih dari 30 Tahun sebanyak 11 responden atau ditunjukkan berdasarkan persentase diperoleh sebesar 25,00 persen $(25,00 \%)$.

Karakteristik demografis dari responden yang membeli laptop Sony Vaio dimana pelanggan yang memiliki pendapatan antara Rp 2.800.000 - 3.000.000 sebanyak 5 responden atau ditunjukkan berdasarkan persentase diperoleh sebesar 11,40 persen $(11,40 \%)$. Karakteristik demografis dari responden yang membeli laptop Sony Vaio dimana pelanggan yang memiliki pendapatan antara $\mathrm{Rp} 3.100 .000$ - 3.500.000 sebanyak 10 responden atau ditunjukkan berdasarkan persentase diperoleh sebesar 22,70 persen (22,70\%). Karakteristik demografis dari responden yang membeli laptop Sony Vaio dimana pelanggan yang memiliki pendapatan antara Rp 3.600.000-4.000.000 sebanyak 17 responden atau ditunjukkan berdasarkan persentase diperoleh sebesar 38,60 persen $(38,60 \%)$. Karakteristik demografis dari responden yang membeli laptop Sony Vaio dimana pelanggan yang memiliki pendapatan lebih dari $\mathrm{Rp} 4.500 .000$ sebanyak 12 responden atau ditunjukkan berdasarkan persentase diperoleh sebesar 21,30 persen $(27,30 \%)$. 
Karakteristik demografis dari responden yang membeli laptop Sony Vaio dimana pelanggan yang memiliki alasan keunggulan dari fitur yang dimiliki dari laptop Sony Vaio sebanyak 15 responden atau ditunjukkan berdasarkan persentase diperoleh sebesar 34,10 persen $(34,10 \%)$. Karakteristik demografis dari responden yang membeli laptop Sony Vaio dimana pelanggan yang memiliki alasan desain dan warna yang menarik dari laptop Sony Vaio sebanyak 7 responden atau ditunjukkan berdasarkan persentase diperoleh sebesar 15,90 persen $(15,90 \%)$. Karakteristik demografis dari responden yang membeli laptop Sony Vaio dimana pelanggan yang memiliki alasan kapasitas penyimpanan yang besar dari laptop Sony Vaio sebanyak 9 responden atau ditunjukkan berdasarkan persentase diperoleh sebesar 20,50 persen $(20,50 \%)$. Karakteristik demografis dari responden yang membeli laptop Sony Vaio dimana pelanggan yang memiliki alasan kualitas produk yang baik dari laptop Sony Vaio sebanyak 13 responden atau ditunjukkan berdasarkan persentase diperoleh sebesar 29,50 persen $(29,50 \%)$.

\section{HASIL DAN PEMBAHASAN}

\section{Hasil Penelitian}

\section{Uji Validitas}

Uji validitas digunakan untuk mengetahui apakah semua item pertanyaan penelitian yang digunakan untuk mengukur variabel penelitian adalah valid. Pengujian validitas dilakukan dengan mencari korelasi dari setiap indikator terhadap skor totalnya dengan menggunakan rumus teknik Pearson Correlation Product Moment dengan bantuan software SPSS versi 17.0 (Sekaran, 2006). Keputusan yang diambil dengan cara membandingkan nilai p-value dari setiap variabel pernyataan $(\alpha=0,05)$. Dasar pengambilan keputusan uji validitas adalah sebagai berikut : Jika $p$-value $<(0,05)$ maka item pernyataan valid. Jika $p$-value $>$ $(0,05)$ maka item pernyataan tidak valid.

Tabel 2.

Hasil Uji Validitas

\begin{tabular}{lccc}
\hline \multicolumn{1}{c}{ Pernyataan } & P-Value & $\begin{array}{c}\text { Koefisien } \\
\text { Korelasi }\end{array}$ & Keputusan \\
\hline $\begin{array}{l}\text { 1. Utilitarian Value } \\
\text { Pelanggan memahami pentingnya } \\
\text { memiliki rencana untuk membeli } \\
\text { laptop Sony Vaio. }\end{array}$ & 0,000 & 0,860 & Valid \\
$\begin{array}{l}\text { Ketika pelanggan berbelanja produk } \\
\text { laptop Sony Vaio, pelanggan } \\
\text { menemukan fitur yang sesuai dengan } \\
\text { keperluan saya. }\end{array}$ & 0,000 & 0,822 & Valid \\
$\begin{array}{l}\text { Pelanggan akan merasa kecewa } \\
\text { apabila pelanggan tidak membeli } \\
\text { produk laptop Sony Vaio. }\end{array}$ & 0,000 & 0,692 & \\
$\begin{array}{l}\text { Pelanggan mengunjungi toko yang } \\
\text { tepat harus diputuskan secara cepat }\end{array}$ & 0,000 & 0,733 & Valid \\
$\begin{array}{l}\text { 2. Hedonic Value } \\
\text { Berbelanja laptop Sony Vaio } \\
\text { menyenangkan. }\end{array}$ & & & \\
\end{tabular}




\begin{tabular}{|c|c|c|c|}
\hline Pernyataan & P-Value & $\begin{array}{c}\text { Koefisien } \\
\text { Korelasi }\end{array}$ & Keputusan \\
\hline $\begin{array}{l}\text { Pelanggan melanjutkan untuk } \\
\text { berbelanja laptop Sony Vaio karena } \\
\text { pelanggan menginginkannya. }\end{array}$ & 0,000 & 0,692 & Valid \\
\hline $\begin{array}{l}\text { Dibandingkan dengan laptop lainnya, } \\
\text { waktu berbelanja yang dihabiskan } \\
\text { oleh pelanggan sangat } \\
\text { menyenangkan. }\end{array}$ & 0,000 & 0,746 & Valid \\
\hline $\begin{array}{l}\text { Pelanggan menikmati keunggulan } \\
\text { fitur terbaru dari laptop Sony Vaio. }\end{array}$ & 0,000 & 0,644 & Valid \\
\hline $\begin{array}{l}\text { Pelanggan menikmati berbelanja } \\
\text { sehingga pelanggan membeli lebih } \\
\text { dari satu jenis laptop Sony Vaio. }\end{array}$ & 0,000 & 0,704 & Valid \\
\hline $\begin{array}{l}\text { Pelanggan memiliki banyak waktu } \\
\text { untuk berbelanja laptop Sony Vaio. }\end{array}$ & 0,000 & 0,758 & Valid \\
\hline $\begin{array}{l}\text { Selama aktivitas berbelanja, saya } \\
\text { senang melakukan aktivitas di dalam } \\
\text { mencari laptop yang baik. }\end{array}$ & 0,000 & 0,724 & Valid \\
\hline $\begin{array}{l}\text { Ketika pelanggan berbelanja, } \\
\text { pelanggan merasa lupa akan masalah } \\
\text { yang dihadapi. }\end{array}$ & 0,000 & 0,627 & Valid \\
\hline $\begin{array}{l}\text { Ketika pelanggan berbelanja, } \\
\text { pelanggan merasa berpetualang. }\end{array}$ & 0,000 & 0,741 & Valid \\
\hline $\begin{array}{l}\text { Berbelanja adalah waktu yang } \\
\text { menyenangkan bagi pelanggan. }\end{array}$ & 0,000 & 0,545 & Valid \\
\hline $\begin{array}{l}\text { 3. Customer Experience } \\
\text { Saya membeli laptop Sony Vaio } \\
\text { karena saya memiliki hobi berbelanja }\end{array}$ & 0,000 & 0,733 & Valid \\
\hline $\begin{array}{l}\text { Saya mencari pengalaman yang } \\
\text { berbeda ketika saya membeli laptop } \\
\text { Sony Vaio. }\end{array}$ & 0,000 & 0,868 & Valid \\
\hline $\begin{array}{l}\text { Ketika saya berbelanja laptop Sony } \\
\text { Vaio, saya mengetahui keunggulan } \\
\text { fitur laptop Sony Vaio dibandingkan } \\
\text { pesaing lainnya. }\end{array}$ & 0,000 & 0,763 & Valid \\
\hline $\begin{array}{l}\text { 4. Brand Trust } \\
\text { Saya merasa yakin terhadap merek } \\
\text { laptop Sony Vaio. }\end{array}$ & 0,000 & 0,944 & Valid \\
\hline $\begin{array}{l}\text { Saya memilih untuk tetap membeli } \\
\text { laptop Sony Vaio. }\end{array}$ & 0,000 & 0,810 & Valid \\
\hline
\end{tabular}




\begin{tabular}{lccc}
\hline \multicolumn{1}{c}{ Pernyataan } & P-Value & $\begin{array}{c}\text { Koefisien } \\
\text { Korelasi }\end{array}$ & Keputusan \\
\hline $\begin{array}{l}\text { Laptop Sony Vaio adalah merek } \\
\text { laptop yang terpercaya. }\end{array}$ & 0,000 & 0,887 & Valid \\
$\begin{array}{l}\text { 5. Brand Loyalty } \\
\begin{array}{l}\text { Saya akan tetap mengunjungi penjual } \\
\text { laptop Sony Vaio di masa yang akan } \\
\text { datang }\end{array}\end{array}$ & 0,000 & 0,858 & Valid \\
$\begin{array}{l}\text { Saya akan membeli laptop Sony Vaio } \\
\text { di masa yang akan datang. }\end{array}$ & 0,000 & 0,887 & Valid \\
$\begin{array}{l}\text { Saya akan merekomendasikan laptop } \\
\text { Sony Vaio kepada teman dan } \\
\text { kerabat. }\end{array}$ & 0,000 & 0,933 & Valid \\
\hline
\end{tabular}

Dalam tabel 2 terlihat hasil uji validitas dari variabel ditelitinya yaitu utilitarian value, hedonic value, customer experience, brand trust, dan brand loyalty diperoleh nilai p-value kurang dari 0,5 maka terlihat variabel yang diteliti yaitu utilitarian value, hedonic value, customer experience, brand trust, dan brand loyalty dapat diukur (Valid).

\section{Uji Reliabilitas}

Suatu uji reliabilitas pada alat ukur perlu dilakukan untuk memastikan instrumen dari alat ukur yang digunakan untuk penelitian ini adalah konsisten dan akurat. Reliabilitas berkaitan dengan konsistensi, akurasi, dan prediktabilitas suatu alat ukur (Hermawan, 2006). Menurut Sekaran (2006), dasar pengambilan keputusan uji reliabilitas ini adalah sebagai berikut :

1. Jika koefisien Cronbach's Alpha $\geq 0,6 \rightarrow$ maka Cronbach's Alpha acceptable (construct reliable)

2. Jika koefisien Cronbach's Alpha $<0,6 \rightarrow$ maka Cronbach's Alpha poor acceptable (construct unreliable)

\section{Tabel 3}

Hasil Uji Reliabilitas

\begin{tabular}{lccc}
\hline \multicolumn{1}{c}{ Variabel } & $\begin{array}{c}\text { Item/ } \\
\text { Pernyataan }\end{array}$ & $\begin{array}{c}\text { Cronbach's } \\
\text { Alpha }\end{array}$ & Keputusan \\
\hline $\begin{array}{l}\text { Utilitarian Value } \\
\text { Hedonic Value }\end{array}$ & 4 & 0,771 & Reliable \\
$\begin{array}{l}\text { Customer } \\
\text { Experience }\end{array}$ & 10 & 0,865 & Reliable \\
$\begin{array}{l}\text { Brand } \\
\text { Trust }\end{array}$ & 3 & 0,698 & Reliable \\
Brand Loyalty & 3 & 0,858 & Reliable \\
\hline
\end{tabular}

Dalam tabel 3 terlihat adanya hasil uji reliabilitas pada variabel yang diteliti adalah utilitarian value, hedonic value, customer experience, brand trust, dan brand loyalty 
diperoleh nilai Cronbach Alpha sebesar lebih dari 0,6 maka variabel yang diteliti terlihat konsisten (reliable).

\section{Statistik Deskriptif}

Statistik deskriptif adalah statistik yang menggambarkan fenomena atau karakteristik dari data yang diteliti dalam suatu situasi (Sekaran, 2006). Statistik deskriptif adalah suatu deskripsi mengenai pengumpulan, penyusunan, serta penyajian data berdasarkan nilai ratarata (Mean) Sntoso, 2008). Hasil statistik dari variabel-variabel utilitarian value, hedonic value, customer experience, brand trust, dan brand loyalty dapat dilihat pada tabel 4 di bawah ini :

Tabel 4

Statistik Deskriptif

\begin{tabular}{lccc}
\hline \multicolumn{1}{c}{ Variabel } & $\mathbf{n = 4 4}$ & Mean & Std. Deviation \\
\hline Utilitarian Value & 44 & 3,65 & 0,64 \\
Hedonic Value & 44 & 3,81 & 0,58 \\
Customer Experience & 44 & 3,81 & 0,55 \\
Brand Trust & 44 & 3,76 & 0,64 \\
Brand Loyalty & 44 & 3,72 & 0,73 \\
\hline
\end{tabular}

Nilai rata-rata dari pembentukan tanggapan terhadap Utilitarian Value diperoleh nilai rata-rata sebesar 3,65 maka menunjukkan responden berpendapat bahwa produk laptop Sony Vaio, pelanggan menemukan fitur yang sesuai dengan keperluan saya dengan standar deviasi sebesar 0,64. Nilai rata-rata dari pembentukan tanggapan terhadap Hedonic Value diperoleh nilai rata-rata sebesar 3,81 maka menunjukkan responden berpendapat bahwa berbelanja laptop Sony Vaio menyenangkan dengan standar deviasi sebesar 0,58. Nilai rata-rata dari pembentukan tanggapan terhadap Customer Experience diperoleh nilai rata-rata sebesar 3,81 maka menunjukkan responden berpendapat bahwa pelanggan mencari pengalaman yang berbeda ketika saya membeli laptop Sony Vaio dengan standar deviasi sebesar 0,55. Nilai rata-rata dari pembentukan tanggapan terhadap Brand Trust diperoleh nilai rata-rata sebesar 3,76 maka menunjukkan responden berpendapat bahwa pelanggan merasa yakin terhadap merek laptop Sony Vaio dengan standar deviasi sebesar 0,64. Nilai rata-rata dari pembentukan tanggapan terhadap Brand Loyalty diperoleh nilai rata-rata sebesar 3,72 maka menunjukkan responden berpendapat bahwa pelanggan merasa yakin terhadap merek laptop Sony Vaio dengan standar deviasi sebesar 0,73.

\section{Hasil Uji Hipotesis}

\section{Tabel 5}

Statistik Deskriptif

\begin{tabular}{lccc}
\hline \multicolumn{1}{c}{ Variabel } & $\boldsymbol{\beta}$ & $\begin{array}{c}\boldsymbol{P} \text { - } \\
\text { Value }\end{array}$ & Keputusan \\
\hline$H_{1}:$ & & & \\
$\begin{array}{l}\text { Utilitarian } \rightarrow \\
\text { Value }\end{array}$ & 0,289 & 0,013 & $\mathrm{Ho}_{1}$ \\
$\begin{array}{l}\text { Brand Loyalty } \\
H_{2}:\end{array}$ & & & ditolak \\
$\begin{array}{l}\text { Hedonic Value } \rightarrow \\
\text { Brand Loyalty }\end{array}$ & 0,252 & 0,020 & $\mathrm{Ho}_{2}$ \\
& & & ditolak
\end{tabular}




\begin{tabular}{lccc}
\hline \multicolumn{1}{c}{ Variabel } & $\boldsymbol{\beta}$ & $\begin{array}{c}\boldsymbol{P} \text { - } \\
\text { Value }\end{array}$ & Keputusan \\
\hline $\mathrm{H}_{3}:$ & & & \\
$\begin{array}{l}\text { Customer } \\
\text { Experience } \\
\text { Brand Loyalty }\end{array}$ & 0,293 & 0,005 & $\mathrm{Ho}_{3}$ \\
$\mathrm{H}_{4}:$ & & & ditolak \\
Brand Trust $\rightarrow$ & & & \\
Brand Loyalty & 0,245 & 0,033 & $\mathrm{Ho}_{4}$ \\
\hline
\end{tabular}

\section{KESIMPULAN DAN SARAN}

\section{Kesimpulan}

Berdasarkan uraian dan analisis yang telah dikemukakan sebelumnya, maka simpulan yang diperoleh dari penelitian ini adalah: Hasil pengujian hipotesis menurut kualifikasi menunjukkan bahwa customer experience memiliki pengaruh positif terhadap brand loyalty. Dengan pengalaman positif yang dimiliki dari dalam diri pelanggan ketika menggunakan laptop Sony Vaio maka dapat menciptakan keinginan membeli laptop Sony Vaio di masa yang akan datang. Hal ini ditunjukkan dengan pelanggan mencari pengalaman yang berbeda ketika saya membeli laptop Sony Vaio sehingga pelanggan akan tetap mengunjungi penjual laptop Sony Vaio di masa yang akan datang.

Penelitian ini diharapkan memberikan masukan bagi manajer pemasaran di suatu toko yang menjual laptop Sony Vaio agar : 1). Dapat menarik minat pelanggan agar cepat mengunjungi took. 2). Dapat memberikan potongan harga khusus bagi pelanggan yang membeli laptop Sony Vaio agar berbelanja lebih menyenangkan. 3). Dapat menetapkan harga yang sesuai dengan produk atau jasa yang dijual kepada pelanggan sehingga tidak terlihat terlalu mahal dengan toko yang lainnya. 4). Dapat menjelaskan fitur terdepan yang dimiliki oleh laptop Sony Vaio agar dapat dipercaya oleh pelanggan. 5). Dapat memberikan kartu member apabila seorang pelanggan telah melakukan pembelian sehingga pelanggan dapat mengunjungi toko tersebut kembali di masa yang akan datang.

\section{Saran}

Saran-saran yang dapat diberikan untuk peneliti selanjutnya antara lain : 1). Penelitian ini hanya menggunakan responden pelanggan yang membeli laptop Sony Vaio di Bekasi Cyber Park tetapi penelitian yang akan datang dapat menggunakan responden pelanggan yang membeli laptop lainnya di mall wilayah lainnya. 2). Penelitian ini tidak hanya meneliti berdasarkan penelitian yang dilakukan oleh Song, et.al., (2012). 3). Penelitian ini tidak hanya meneliti mengenai pengaruh utilitarian value, hedonic value, customer experience, brand trust terhadap brand loyalty melalui analisis regresi berganda tetapi dapat menguji menggunakan teknik Structural Equation Model (SEM).

\section{DAFTAR PUSTAKA}

Arnould, Price and Zinkhan. (2002). Consumers. New York: McGraw-Hill.

Brakus, J. Josko, Bernd H. Schmitt, and Shi Zhang (2008), "Experiential Attributes and Consumer Judgments, " in Handbook on Brand and Experience Management, Bernd $\mathrm{H}$. Schmitt and David Rogers, eds. Northampton, MA : Edward Elgar. 
Carpenter, J.M. (2008), "Consumer Shopping Value, Satisfaction and Loyalty in Discount Retailing", Journal of Retail Consumer. Service, Vol.15 No.(5), pp.358-363

Chahal, Hardeep; Bala, Madhu. (2012), "Confirmatory Study On Brand Equity And Brand Loyalty: A Special Look At The Impact Of Attitudinal And Behavioral Loyalty", Vision, Vol.14 No.1/2 (Jan-Jun 2010), pp. 1-12.

Chaudhuri dan Holbrook, (2001), "The Chain of Effects from Brand Trust and Brand Affect to Brand Preformance: The Role of Brand Loyalty". Journal of Market Focused Management.

Chang, E. (2002), "The mediating role of Shopping value in apparel shopping satisfaction", PHD. Dissertation, Oregon State University.

Chen, Z. (2004), "Consumers' value perception of an e-store and its impact on e-store loyalty intention”, Dissertation Abstract International, Vol.64 (11), 4218. (UMI No.3113784).

Delgado, J., Mateos, M.A., Benitez, T. (2003), "Glucose uptake in Trichoderma Harizanum: role of gtt1", Eukaryot. Cell, Vol.2, pp. 708-717

Delgado-Ballester, Elena: Josa, Luis Munuera-Aleman (2005), “Does Brand Trust Matter To Brand Equity?", The Journal of Product and Brand Management, 14.2/3 (2005): 187196.

Ding, D.X., Hu P.J., Verma R. and Wardell D.G., (2010), "The Impact of Service System Design and Flow Experience on Customer Satisfaction in Online Financial Services", Journal of Service Research, 13 (1) 96-110.

Fajrianti, Z.F. (2005), "Strategi Perluasan Merek dan Loyalitas Konsumen”, Jurnal Bisnis Manajemen, Vol.7, No.3

Giddens, Nancy. (2002), Brand Loyalty, Missouri Value-added Development. Center

Gommans, M., Krishman, K.S., and Scheffold, K.B (2001), "From brand loyalty to e-loyalty: A conceptual framework", Journal of Economic \& Social Research, Vol.3 No.(1), pp. $43-58$

Grewal, D., Levy, M., Kumar, V. (2009),'Customer Experience Management in Retailing: An Organizing Framework", Journal of Retailing, Vol.85. No.1, pp.1-14

Griffin, J., (2002). Customer Loyalty: How to Earn It, How to Keep It, New and Revised Edition, Weekly publisher.

Ha, H.Y., J.John, S. Janda and S. Muthaly, (2011), "The effect to advertising spending on brand loyalty in services", European Journal of Marketing, Vol.45 No.(4), pp.673-691.

Hanzaee, H.K. and Andervazh, L. (2012), "An Analysis of Some Moderating Variables on the Value, Brand Trust and Brand Loyalty Chain", Research Journal of Applied Sciences, Engineering and Technology, Vol.4 No.(10), pp.1403-1413.

Hermawan, A., (2006), Penelitian Bisnis Paradigma Kuantitatif, Jakarta: Grasindo.

Hu, L.F. and Chuang, C.C. (2012). "A Study of the Relationship Between the Value Perception and Loyalty Intention Toward an E-Retailer Website", Journal of Internet Banking and Commerce, Vol. 17, no.1, pp.1-18.

Iglesias, Oriol, Singh, Jatinder J. and Batista-Foguet, Joan M. (2011), "The Role of Brand Experience and Affective Commitment in Determining Brand Loyalty", Brand Management, Vol.18 No.8, pp.570-580.

Irani, N, and Hanzaee, K.H. (2011), "The Effects of Variety-seeking Buying Tendency and Price Sensitivity on Utilitarian and Hedonic Value in Apparel Shopping Satisfaction", International Journal of Marketing Studies. 3.3 (Aug 2011): 89-103

Johnston, R. and Clark, G. (2008), Service operations management. Pearson education limited, UK.

Johnston, R. and Kong, X. (2011), "The customer experience: a road-map for improvement", Managing Service Quality, Vol.21 No.1, pp.5-24. 
Knight, D.K., and E.Y. Kim. (2007), "Japanese consumers' needforuniqueness: Effects on brand perceptions and purchase intention", Journal of Fashion Marketing and Management, Vol.11 No.(2), pp.270-280.

Kuenzel, S. \& Halliday, V. (2010), "The Chain of Effect from Reputation and Brand personal Congruence to Brand Loyalty: The Effect of Brand Identification", Journal of Targeting, Measurement and Analysis for Marketing, Vol.18 No.(3/4), pp.167-176

Lee, E.J. and Overby, J.W. (2004), "Creating Value for Online Shoppers: Implications for Satisfaction and Loyalty", Journal of Consumer Satisfaction, Dissatisfaction and Complaining Behavior, 17 (2004): 54-67

Lin, C., Wu, W.Y. and Wang, Z.F. (2000), "A study of market structure: brand loyalty and brand switching behaviours for durable household appliances", International Journal of Market Research, Vol.42 No.3, pp.277-300. Veloutosou, 2004)

Matzler, K., Bidmon, S. And Grabner-Krauter, S. (2006), "Individual determinants of brand affect: the role of the personality traits of extraversion and openness to experience", Journal of Product \& Brand Management, Vol.15 Iss: 7, pp.427-434

Matzler, K., Grabner-Krauter, S. And Sonja Bidmon, (2008), "Risk aversion and brand loyalty: the mediating role of brand trust and brand affect", Journal of Product \& Brand Management, Vol.17 Iss: 3, pp.154-162.

Meyer, C. \& Schwager, A. (2007),'Understanding Customer Experience", Harvard Business Review, Vol.85 No.(2), pp.116-126

Odin, Y.,Odin, N. and Valette-Florence, P. (2001), "Conceptual and operational aspects of brand loyalty: an empirical investigation", Journal of Business Research, Vol.53 No.2, pp.75-84.

Ok, C., Choi, Y.G., Hyun, S.S. (2011), "Roles of Brand Value Perception in the Development of Brand Credibility and Brand Prestige", International CHRIE Conference-Refereed Track, Vol.27 No.2, pp.1-9.

Overby, J.W.\& Lee, E.J. (2006), "The effects of utilitarian and hedonic online shopping value on consumer preference and intentions", Journal of Business Research, Vol.59 No.(10/11), pp.1160-1166.

Palmer, A. (2010), "Customer experience management: acritical review of an emerging idea", Journal of Services Marketing, Vol.24/3, pp.196-208

Park, C.W., Mac Innis, D.J., Priester, J. (2006), "Beyond attitude: Attachment and consumer behavior", Seoul Journal of Business, Vol.2 No.12

Pucinelli, Nancy M, Ronald C, Gooodstein, Dhruv Grewal, Robert Price, Priya Raghubir and David Stewart (2009), Customer Experience Management in Retailing: Understanding the Buying Process", Journal of Retailing, Vol.85 No.(1), pp.15-30

Quester, P. and Lim, A.L. (2003), "Product involvement/brand loyalty: is there a link?", Journal of Product \& Brand Management, Vol.12 No.1, pp.22-38.

Rintamaki, Timo; Kuusela, Hannu; Mitronen, Lasse. (2007), "Identifying competitive customer value propositions in retailing", Managing Service Quality, Vol.17 No.6, pp.621-634

Ryu, K., Han, H. and Jang, S.S. (2010), "Relationships among hedonic and utilitarian value, satisfaction and behavioralintentions", International Journal of Contemporary Hospitality Management, Vol.22 Iss: 3, pp.416-432

Schifman \& Kanuk. (2004). Perilaku Konsumen (edisi 7). Jakarta : Prentice Hall.

Sekaran, U. (2006), Research methods for business ( $4^{\text {th }}$ ed), John Wiley \& Sons, New York.

Seo, S. and Lee, Y. (2008), "Shopping values ofclothing retailers perceived by consumers of different social classes", Journal of Retailing and Consumer Services, Vol.15 No.6, pp.491-499. 
Shang, R.A., Yu-Chen, Chen: Hsueh-Jung Liao. (2006), "The valkue of participation in virtual consumer communities on brand loyalty", Internet Research, Vol. 16 No.4, pp.398

Sindhav, B. And Adidam, P.T. (2012), "Hedonic and Utilitarian Values of a Service Experience with a Nonprofit", International Management Review, Vol.8 No.1, pp.37-43

Song, Y., Hur, W.M. and Kim, M. (2012), "Brand Trust and Affect In The Luxury BrandCustomer Relationship", Social Behavior and Personality; 2012; 40, 2; ProQuest, pp.331.

Teo, T. (2001), "Demographic and motivation variables associated with Internet usage activities", Internet Research, Vol.11 No.(2), pp.125-37

Van Riel, A.C.R., Liljander, V., \& Jurriens, P. (2001), "Exploring consumer evaluations of eservices", International Journal of Service Industry Management, 12, pp.359-377.

Van den Brink, D. Gaby Odekerben-Schroder, Pieter Pauwels. (2006), "The effect os strategic and tactical cause-related marketing on consumers' brand loyalty", Emerald 23.

Zboja, J.J. and Voorhees, C.M. (2006), "The impact of brand trust and satisfaction on retailer repurchase intentions", Journal of Service Marketing, Vol.20 Iss: 6, pp.381-390. 